some instances, which has resulted in higher rates of preventable illnesses and even deaths.

"When people delay or fail to receive primary care and preventive services, everyone pays the price," says the report, which was issued by Senator Bernard Sanders, I-Vt, chair of the Senate HELP subcommittee. "It is not only our moral responsibility to ensure primary care access now and into the future, but it is fiscally sensible to act quickly to expand this critical workforce."

According to the report, the "evidence is clear that access to primary health care results in better health outcomes, reduced health disparities and lower spending, including on avoidable emergency room visits and hospital care. ... Primary care is intended to be, and should be, the foundation of the US health care system."

Yet, the shortage of primary care physicians and other primary care health professionals has reached critical mass, says the report. Nearly 57 million people in the United States - 1 in 5 Americans - now live in areas that lack adequate access to primary care. As a consequence, millions of Americans use the emergency room for care that could have been provided by a primary care physician. Specifically, one-half of emergency room patients could have obtained care from a primary care physician if they had been able to obtain an appointment when care was needed, according to the report.

"Visits to emergency rooms are not only more expensive, but the lack of continuity in care can result in extra tests, limited follow-up care and an increased risk for medical errors," says the report. "Also, acute, nonurgent cases can crowd emergency rooms, making it more challenging for emergency room physicians to provide care to the most serious cases."

The need for primary care physicians will become even more severe as the Patient Protection and Affordable Care Act extends health care coverage to millions more people during the next few years. According to the report, the nation will need 52,000 primary care physicians by 2025, a demand that will not be met based on current trends.

"In 2011, about 17,000 doctors graduated from American medical schools," the report says. "Despite the fact that over half of patient visits are for primary care, only $7 \%$ of the nation's medical school graduates now choose a primary care career."

Additionally, the average primary care physician in the United States is 47 years old, and one-quarter are nearing retirement, a trend that will further exacerbate the growing shortage.

The report cites other reasons for the growing shortage of primary care physicians, as well, including the wide income disparity between subspecialists and primary care physicians that acts as a disincentive to pursuing primary care.
The report also discusses the AMA/Specialty Society Relative Value Scale Update Committee (RUC). It describes the 31-member committee as dominated by subspecialists and largely responsible for setting physician payment rates. "Therefore, it should come as no surprise that it (the RUC) has accelerated higher payments-larger paychecks - to (sub)specialists over primary care doctors," says the report.

Medicare, meanwhile, encourages the growth of subspecialty residencies by providing about $\$ 10$ billion a year to teaching hospitals "without requiring any emphasis on training primary care doctors. Because of the strong financial incentives to train (sub)specialists, many hospitals have shifted away from training primary care doctors over time," the report says.

There are various ways of addressing the ongoing shortage of primary care physicians and other primary care health professionals, says the report. It recommends increasing primary care scholarship and loanrepayment programs and opportunities in education and residencies for primary care training in community settings. For example, the Affordable Care Act has created the Teaching Health Centers program to move training outside of hospitals and into communities, where most health care is delivered.

The Affordable Care Act provides $\$ 230$ million for the Teaching Health Centers program from 2011-2015, which is a small percentage of overall graduate medical education spending and is enough to produce 600 new primary care residents by 2015, according to the report. "Although these physicians will serve thousands of patients, the scope of the need in this country is so great that this program must be dramatically expanded."

James Arvantes

AAFP News Now

From the American

Board of Family Medicine

Ann Fam Med 2013;11:185-187. doi:10.1370/afm.1524.

\section{CRITERION-REFERENCED EXAMINATIONS: IMPLICATIONS FOR THE REPORTING AND INTERPRETATION OF EXAMINATION RESULTS}

The purpose of the American Board of Family Medicine (ABFM) certification/maintenance of certification examination is to measure the basic knowledge 
necessary to deliver high quality care to patients and their families. More than 25 years ago, the ABFM became the first American Board of Medical Specialties (ABMS) board to introduce criterion-based methodology to establish the passing threshold for its examination. A criterion-referenced examination is one in which a particular score is required to pass, and the performance of those taking the exam is of no consequence in determining who passes or fails. In other words, all candidates taking the examination could theoretically pass if they met or exceeded the criterion-referenced passing score. Furthermore, the exam is equated across forms and administration, meaning candidates are not advantaged or disadvantaged by having received a particular version of the exam, or by taking it at a particular time of the year.

It should be apparent, therefore, that the ABFM is not interested in comparing the performance of one candidate with another, but rather comparing a candidate's performance against the criterion-based passing threshold. Our ability to do so became more precise in 2006 when we moved to a new psychometric model, Item Response Theory (IRT), to develop and score the examination. Among its many advantages over the Classical Test Theory model that we had previously employed for over 35 years, IRT provides greater discrimination and precision around the passing threshold. However, it also provides less useful information for those who score very well or very poorly, and that is one of the major reasons why we have recently discontinued the use of percentile ranks associated with a candidate's score. Reporting percentile ranks can be problematic and potentially misleading for examinees, and we would like to demonstrate why that is so.

Since candidates that apply for the examination consist of both recently trained residents seeking certification for the first time as well as seasoned family physicians seeking to maintain their certification, the cohort of family physicians who sit for the examination each year is quite diverse. The demographic characteristics, experience levels, geographic location and even scope of practice of the physicians in each sample vary considerably. This was particularly true with the cohorts that took the examination in 2010, 2011, and 2012.

Prior to 2005, the ABFM granted certification for 7 -year periods. Beginning in 2005, a policy change was implemented within our Maintenance of Certification for Family Physicians (MC-FP) program that created the possibility for family physicians to earn a 3 -year extension of their certificate, thereby extending the period of time between examinations by 10 years. As a result of this policy change, the ABFM experienced a 3-year period in which the number of family physicians seeking to maintain their certification was very low. However, the number of family physicians who had previously failed and were attempting to recertify was disproportionately high. This phenomenon is best demonstrated by comparing the 2009 and 2010 exam cohorts.

In the table below, percentile ranks are reported for both the 2009 and 2010 MC-FP exams. The passing standard for the exam in both years was 390 with a reported scaled score range of 200 to 800 . Because the cohorts of initial certifiers (primarily residents) in 2009 and 2010 were relatively stable, the percentile rank did not change much from 2009 to 2010 (about 2 percentile points) for these candidates. However, for those

Table 1. Percentile Rank Comparisons for Initial Certifiers and Recertifiers for 2009 and 2010.

\begin{tabular}{|c|c|c|c|c|}
\hline \multirow{2}{*}{$\begin{array}{l}\text { Scaled } \\
\text { Score }\end{array}$} & \multicolumn{2}{|c|}{$\begin{array}{l}\text { Initial Certification } \\
\text { Candidates }\end{array}$} & \multicolumn{2}{|c|}{ MC-FP Candidates } \\
\hline & 2009 & 2010 & 2009 & 2010 \\
\hline 300 & 2 & 3 & 3 & 10 \\
\hline 310 & 3 & 3 & 4 & 11 \\
\hline 320 & 4 & 4 & 5 & 13 \\
\hline 330 & 4 & 5 & 6 & 15 \\
\hline 340 & 6 & 7 & 7 & 17 \\
\hline 350 & 7 & 8 & 8 & 19 \\
\hline 360 & 9 & 10 & 9 & 22 \\
\hline 370 & 11 & 12 & 11 & 25 \\
\hline 380 & 13 & 15 & 13 & 28 \\
\hline $390^{\mathrm{a}}$ & 16 & 18 & 15 & 31 \\
\hline 400 & 19 & 21 & 17 & 34 \\
\hline 410 & 22 & 24 & 19 & 37 \\
\hline 420 & 26 & 28 & 22 & 41 \\
\hline 430 & 30 & 32 & 24 & 44 \\
\hline 440 & 34 & 36 & 27 & 48 \\
\hline 450 & 38 & 40 & 30 & 51 \\
\hline 460 & 43 & 45 & 34 & 55 \\
\hline 470 & 47 & 49 & 37 & 59 \\
\hline 480 & 52 & 54 & 40 & 62 \\
\hline 490 & 56 & 58 & 44 & 65 \\
\hline 500 & 61 & 63 & 47 & 69 \\
\hline 510 & 65 & 67 & 51 & 72 \\
\hline 520 & 69 & 71 & 54 & 75 \\
\hline 530 & 73 & 75 & 58 & 77 \\
\hline 540 & 77 & 78 & 61 & 80 \\
\hline 550 & 80 & 81 & 65 & 82 \\
\hline 560 & 83 & 84 & 68 & 85 \\
\hline 570 & 86 & 87 & 71 & 87 \\
\hline 580 & 89 & 89 & 74 & 89 \\
\hline 590 & 91 & 91 & 77 & 90 \\
\hline 600 & 92 & 93 & 79 & 92 \\
\hline 610 & 94 & 94 & 82 & 93 \\
\hline 620 & 95 & 95 & 84 & 94 \\
\hline 630 & 96 & 96 & 86 & 95 \\
\hline 640 & 97 & 97 & 88 & 96 \\
\hline 650 & 98 & 98 & 90 & 97 \\
\hline
\end{tabular}


attempting to maintain their certification, a scaled score of 390 in 2009 meant one was in the 15 th percentile. In 2010, however, that same scaled score meant one was in the 31st percentile. One will note other significant differences when scanning Table 1 as well.

Interestingly, many examinees can recall their percentile ranking but cannot recall their scaled score. It is easy to understand why some examinees may be interested in learning how well they performed relative to their peers. Yet, from the example shown above, it is evident that percentile rankings may be misleading for both examinees and the general public. When the ranking portrays the examinee as being more knowledgeable than he or she truly is, it inflates and misrepresents one's perceived ability and misleads the public. For example, consider an MC-FP candidate in 2010 that scored a 450 on the exam and wants to compare the ranking with other candidates. This examinee would rank in the 51st percentile among his or her MC-FP peers, but only in the 40th percentile when compared with candidates seeking initial certification.

The practice of reporting percentile rankings has the potential to introduce other undesirable elements into the score reporting process as well. For example, the very nature of reporting percentile ranks will no doubt mean some people will be pleased with their ranking, while others will not. After all, persons at the top end of the scale will certainly feel great about themselves knowing they outperformed the vast majority of their peers on a national examination. However, for those unfortunate examinees that happened to fail the exam it can be rather embarrassing to realize that say, $96 \%$ of one's peers performed better than he or she did. When an examination is criterion-referenced, the only thing that really matters is one's performance relative to the minimum passing standard. After all, someone that scores a 500 on the MC-FP examination is not "more certified" than someone that passed with a score of 400 . We contend that through reporting scores properly and directing examinees toward the appropriate criteria for making meaningful inferences, we can be more responsible with our score reporting while concurrently preserving the dignity of those that inevitably fail.

Kenneth D. Royal, PbD, and James C. Puffer, MD

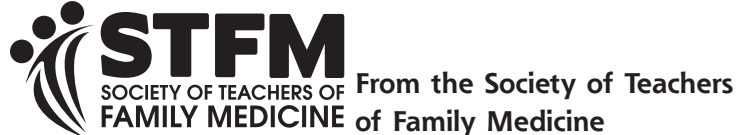

Ann Fam Med 2013;11:187-188. doi:10.1370/afm.1527.

\section{STFM EXAMINES ITS GOVERNANCE STRUCTURE}

STFM has begun a careful study of its governance structure. The goal is to ensure that the Society is making the most effective decisions in the most efficient way possible and that the decisions are in the best interests of the organization and its members. Governance refers to the way in which decisions are made within STFM and involves actions of the Board and committees, especially as they involve allocation of STFM's resources. A governance task force has been charged with the responsibility for making recommendations to the STFM Board. The members of the task force offer a balance among past and current leaders, as well as members of the current STFM Board and committees.

\section{Task Force Members}

Victoria Gorski, MD, Montefiore Medical Center, Governance Task Force chair

Stacy Brungardt, CAE, Society of Teachers

of Family Medicine, Leawood, Kansas

Dan Castro, MD, Harbor UCLA Medical Center,

Torrance, California

Sam Cullison, MD, Swedish FMR Cherry Hill

Campus, Seattle, Washington

Scott Fields, MD, MHA, Oregon Health \& Science

University, Portland, Oregon

Melly Goodell, MD, Medstar Franklin Square

Medical Center, Baltimore, Maryland

Larry Halverson, MD, Cox Health FMR,

Springfield, Missouri

Jeri Hepworth, PhD, University of Connecticut

St. Francis Hospital Family Medicine Residency

Program, Hartford, Connecticut

Ben Miller, PsyD, University of Colorado,

Denver, Colorado

Beat Steiner, MD, MPH, University of North Caro-

lina, Chapel Hill, North Carolina

Rick Streiffer, MD, University of Alabama,

Tuscaloosa, Alabama

Mary Theobald, MBA, Society of Teachers

of Family Medicine, Leawood, Kansas

STFM has not begun this project because of any major problems or concerns. Just as it is good practice for patients to receive periodic check-ups regarding their health, it is also a good practice for STFM to 